\title{
Keloid scarring or disease: unresolved quasi-neoplastic tendencies in the human skin
}

DOI:

10.1111/wrr.12793

\section{Document Version}

Accepted author manuscript

Link to publication record in Manchester Research Explorer

\section{Citation for published version (APA):}

Ud-Din, S., \& Bayat, A. (2020). Keloid scarring or disease: unresolved quasi-neoplastic tendencies in the human skin. Wound Repair and Regeneration. https://doi.org/10.1111/wrr.12793

\section{Published in:}

Wound Repair and Regeneration

\section{Citing this paper}

Please note that where the full-text provided on Manchester Research Explorer is the Author Accepted Manuscript or Proof version this may differ from the final Published version. If citing, it is advised that you check and use the publisher's definitive version.

\section{General rights}

Copyright and moral rights for the publications made accessible in the Research Explorer are retained by the authors and/or other copyright owners and it is a condition of accessing publications that users recognise and abide by the legal requirements associated with these rights.

\section{Takedown policy}

If you believe that this document breaches copyright please refer to the University of Manchester's Takedown Procedures [http://man.ac.uk/04Y6Bo] or contact uml.scholarlycommunications@manchester.ac.uk providing relevant details, so we can investigate your claim.

\section{OPEN ACCESS}




\section{WOUND REPAIR \\ AND \\ REGENERATION}

\section{Keloid scarring or disease: unresolved quasi-neoplastic tendencies in the human skin}

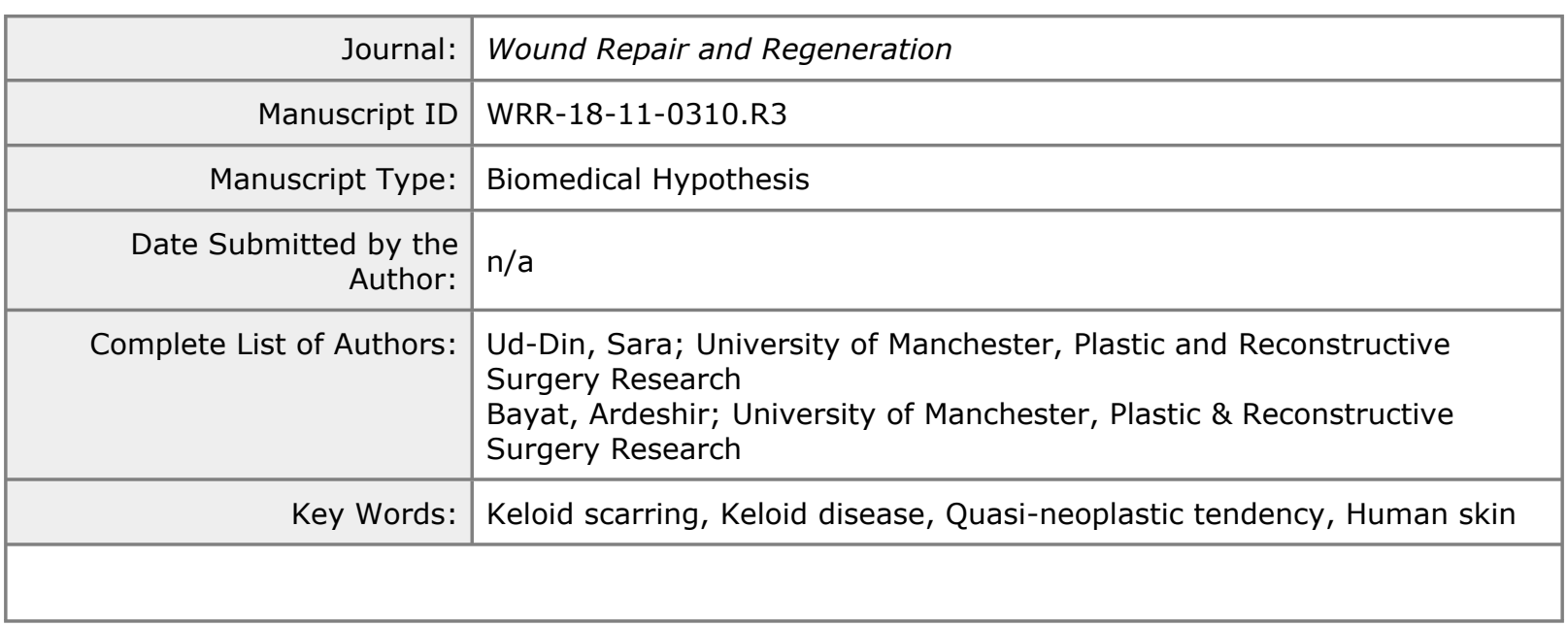

\section{SCHOLARONE ${ }^{\text {m }}$ Manuscripts}




\section{Keloid scarring or disease: unresolved quasi-neoplastic tendencies in the human skin}

Sara Ud-Din, $\mathrm{MSc}^{1}$; Ardeshir Bayat, $\mathrm{PhD}^{1^{*}}$

${ }^{1}$ Plastic and Reconstructive Surgery Research, Centre for Dermatology Research, NIHR Manchester Biomedical Research Centre, University of Manchester, England, United Kingdom.

\section{*Corresponding Author:}

Dr Ardeshir Bayat MB BS PhD

Centre for Dermatology Research

NIHR Manchester Biomedical Research Centre

Stopford Building

University of Manchester

Oxford Road

Manchester

M13 9PT

England, UK.

Tel: 01613060607

Email: ardeshir.bayat@manchester.ac.uk

Conflict of interest: None

Sources of funding: None

Running head: Keloid scarring or disease 


\begin{abstract}
Keloids are benign fibroproliferative dermal scars of unknown aetiopathogenesis resulting in an exophytic protuberant growth with persistent and progressive perilesional expansile behaviour. Keloids are likened to benign neoplastic lesions due to their aggressive clinical behavior, genotypic-phenotypic tissue-characteristics and resistance to treatment. Keloids are traditionally viewed as scars on the healing spectrum, however keloids are a distinct pathology provoked by cutaneous injury rather than a continuum. In order to elucidate the aetiopathogenesis of keloids, the distinction between scar and disease must be made. Therefore, we hypothesize that the link between keloids and their quasi-neoplastic tendencies distinguish it as a disease rather than a scar alone. The biomarker expression profile in these diseases highlights the striking parallels between keloids and both benign and malignant mesenchymal tumors. Signaling pathways common to these diseases have been found to guide the matrix composition of keloids. This hypothesis underscores the need to identify keloids as a disease in order to develop targeted therapy, which can lead to enhanced diagnosis and theranosis.
\end{abstract}




\section{Biomedical Hypothesis}

Keloids present as benign fibroproliferative reticular dermal tumors of unknown aetiopathogenesis that can occur following any dermal trauma leading to an exophytic protuberant growth that invades into the adjacent normal skin beyond the site of the original injury (Figure 1a). ${ }^{1}$ Keloids display unique features of aggressive, persistent and progressive peri-lesional expansile behavior. Other scar types do not behave in this manner and respond well to monotherapy alone unlike keloids, which can recur after any treatment modality. Phenotypically, keloids are consistent with nonmalignant dermal tumors due to the excessive overproduction of collagen and they never metastasize. However, the morphology and clinically aggressive behaviour of keloids is thought to bear a resemblance to neoplastic dermal tumors. Keloids are traditionally viewed as scars on the healing spectrum, however keloids are a distinct pathology provoked by cutaneous injury rather than a continuum. In order to elucidate the aetiopathogenesis of keloids, however, the distinction between scar and disease must be made. Therefore, we hypothesize that the link between keloids and their quasi-neoplastic tendencies distinguish it as a disease rather than a scar alone (Figure $1 b)$.

Although keloids are not routinely classified as true neoplasms due to their lack of spontaneous occurrence and absence of metastasis, they can display various cancerlike characteristics such as uncontrolled proliferation, vascularization, lack of spontaneous regression and invasiveness into surrounding tissue. ${ }^{2}$ Their locally aggressive clinical phenotype suggests possible links with skin or mesenchymal tumors that need to be explored in further detail. There is potentially a key regulator or group of pre-requisite factors, which when activated after skin injury, triggers a 
cascade of events that culminate in KD formation. The various relationships between tumour-related factors expressed in keloids are complex and their roles in sustaining keloid growth are still unclear. ${ }^{3}$

Neoplasia is known as new growth and the terms benign and malignant correlate to the course of the neoplasm. Benign neoplasms remain localised in one area, whilst malignant neoplasms invade the surrounding tissue and, in most cases, can metastasize to other organs. In order to become neoplastic, a normal cell develops mutations enabling it to no longer be confined to the boundaries of adjacent cells, therefore, leading to uncontrolled growth and the ability to produce its own blood supply. ${ }^{4}$ This is also evident in the clinical behaviour of $\mathrm{KD}$ as it invades healthy surrounding skin and is characterised by excessive fibroproliferation associated with significant increases in collagen synthesis and deposition, gradual expansion beyond the boundaries of the original wound and lacking in spontaneous regression.

Gene expression patterns of biopsy tissue and cultured fibroblasts from different anatomical sites within KD (margin versus centre) have been investigated, and shown to display a signature of candidate genes which appear unique to those lesional sites, furthermore confirming the oncologic behaviour displayed by KD. ${ }^{5}$ Extralesional excision of the margins has been advocated for skin cancers, which correlates with emerging role of active cells found at the margin of KD.

It has long been known that $\mathrm{KD}$ often tend to develop in body regions constantly subject to skin mechanical tension. The effects of stretching and tension on KD have shown an overexpression of tension-related proteins. Cellular tension influences tissue 
rheology, epidermal homeostasis and tumor growth and progression in squamous cell carcinoma. ${ }^{6}$ Furthermore, increased tissue rigidity from extracellular matrix (ECM) accumulation in the stroma causes enhanced tumour cell growth and the organisation of collagen fibers at the edge of stromal tumours promote tumor cell invasion and metastasis. Fibroblasts exert an opposing contractile force on the ECM through tensional homeostasis. Alterations in this mechanism can lead to the promotion of fibroblasts to differentiate into cancer associated fibroblasts which results in enhanced contraction.

Tissue hypoxia is a hallmark of tumors and has been shown to increase macrophage migration inhibitory factor expression in tumor cells. ${ }^{7,8}$ The similarity in the hypoxic microenvironment in solid tumors and $\mathrm{KD}$ led to the study of the response of $\mathrm{KD}$ fibroblasts to hypoxia and hypoxia-mimetic agents. ${ }^{7}$ Keloid fibroblasts showed bioenergetics of cancer cells by generating ATP mainly from glycolysis as demonstrated by increased lactate production.

Both keloids and neoplastic lesions have over-active signaling pathways, therefore, we consider examples of the implications of genetic alterations in critical components in these pathways or upstream activators. There has been a reported association between fibrosis and poor prognosis in several cancers. ${ }^{9}$ Fibrosis in cancer is induced by cancer-associated fibroblasts or myofibroblasts, which can induce epithelialmesenchymal transition (EMT) and cancer cell migration. ${ }^{10}$ There is a growing body of evidence recognizing the importance of EMT in keloid pathophysiology. Whilst EMT is known to promote the migratory behavior of metastatic cells, the benign nature of keloids makes it unclear whether they are the result of type II fibrotic EMT 
or suspended type III metastatic EMT. ${ }^{10}$ There is no evidence of significant epidermal-dermal basement membrane breakdown or disrupted collagen IV expression in keloids which may explain why they do not metastasize. Investigating other cell motility factors in keloids may reveal unique key agents in metastatic prevention. Inhibition of the mTOR pathway has recently become of major interest in the control of tumor growth as it regulates cell mobility, survival, proliferation, transcription, and protein synthesis. ${ }^{11}$ It has been reported that KD tissue contains elevated levels of activated mTOR and may be a plausible target pathway in management of KD. This has also been shown in a study on the anti-tumor effects of the mTOR inhibitor everolimus against melanoma. Growing evidence implicates Notch signaling in the regulation of tissue homeostasis such as regulation of endothelial cell proliferation and migration during angiogenesis in normal tissue and tumors. ${ }^{12}$ Aberrant Notch signaling may contribute directly to skin pathogenesis and altered expression of Notch receptors identified in KD. ${ }^{13}$ Several microarray studies have shown overexpression of JAG-1 in KD compared to normal skin fibroblasts. Abnormal Notch signaling is seen in many skin cancers and thus, research has focused on how the inhibition of Notch signaling can lead to growth arrest and differentiation in those cells and how this can represent a target for cancer therapy. Retinoic acid (RA) is a signaling pathway that plays an important role in tissue regeneration and has been shown to induce squamous cell carcinoma tumour regression. ${ }^{14}$ In addition, a study identified up-regulation of the aldo-keto reductase AKR1B10, a key enzyme in RA metabolism in KD epidermis. ${ }^{15}$

In conclusion, keloid presents with quasi-neoplastic genotypic and phenotypic characteristics with morbid cancer-like behaviour due to its aggressive progressive 
nature as it invades into unscarred surrounding skin beyond the site of the original lesion. KD shows a persistent recurrent phenotype following even the most severe oncologic treatments. The notion that keloids behave like non-malignant locally aggressive cutaneous cancers is not new and this is evident in both its phenotypical and genetic properties (Figure 2a). However, the biomarker expression profile in these diseases highlights the parallels between keloids and both benign and malignant mesenchymal tumors (Figure 2b). Signaling pathways common to these diseases have been found to guide the matrix composition of keloids. This leads to many questions in relation to keloid pathobiology which need to be answered, in order to understand how these quasi-neoplastic processes result in keloid formation. Adoption of this hypothesis could enable better understanding of the mechanistic basis for development of keloid and in turn could lead to development of targeted therapy, which can lead to enhanced diagnosis and theranosis.

\section{Acknowledgements \\ Conflict of interest: None \\ We would like to acknowledge the National Institute for Health Research Manchester Biomedical Research Centre (NIHR Manchester BRC) for their support and funding and Helen Carruthers (Medical Illustrations) for assisting with the figure diagrams.}




\section{References}

1. Ud-Din S, Bayat A. Strategic management of keloid disease in ethnic skin: a structured approach supported by the emerging literature. $\mathrm{Br} J$ Dermatol 2013;169:71-81.

2. Ud-Din S, Bayat A. New insights in keloids, hypertrophic scars and striae. Dermatol Clin 2014;32:193-209.

3. Ogawa, R.; Akaishi, S. Endothelial dysfunction may play a key role in keloid and hypertrophic scar pathogenesis-Keloids and hypertrophic scars may be vascular disorders. Med. Hypotheses 2016, 96, 51-60.

4. Srivastava S, Grizzle WE. Biomarkers and the genetics of early neoplastic lesions. Cancer Biomark 2010;9:41-64.

5. Seifert O, Bayat A, Geffers R, Dienus K, Buer J, Löfgren S, et al. Identification of unique gene expression patterns within different lesional sites of keloids. Wound Repair Regen 2008;16:254-65.

6. Samuel MS, Lopez JI, McGhee EJ, Croft DR, Strachan D, Timpson P, et al. Actomyosin-mediated cellular tension drives increased tissue stiffness and $\beta$ catenin activation to induce epidermal hyperplasia and tumor growth. Cancer Cell 2011;19:776-91.

7. Zhang Z, Nie F, Kang C, Chen B, Qin Z, Ma J, et al. Increased periostin expression affects the proliferation, collagen synthesis, migration and invasion of keloid fibroblasts under hypoxic conditions. Int J Mol Med 2014a;34:25361.

8. Zhu G, Peng F, Gong W, She L, Wei M, Tan H, et al. Hypoxia promotes migration/invasion and glycolysis in head and neck squamous cell carcinoma via an HIF-1 $\alpha$-MTDH loop. Oncol Rep 2017;38:2893-2900. 
9. Yan L, Cao R, Wang L, Liu Y, Pan B, Yin Y et al. Epithelial-mesenchymal transition in keloid tissues and TGF- $\beta 1$-induced hair follicle outer root sheath keratinocytes. Wound Repair Regen 2015; 23:601-10.

10. Hahn JM, McFarland KL, Combs KA, Supp DM. Partial epithelialmesenchymal transition in keloid scars: regulation of keloid keratinocyte gene expression by transforming growth factor- $\beta 1$. Burns Trauma 2016;4:30.

11. Syed F, Sherris D, Paus R, Varmeh S, Singh S, Pandolfi PP, Bayat A. Keloid disease can be inhibited by antagonizing excessive mTOR signaling with a novel dual TORC1/2 inhibitor. Am J Pathol 2012;181:1642-58.

12. Syed F, Bayat A. Notch signaling pathway in keloid disease: enhanced fibroblast activity in a Jagged-1 peptide-dependent manner in lesional vs. extralesional fibroblasts. Wound Repair Regen 2012;20:688-706.

13. Han B, Fan J, Liu L, Tian J, Gan C, Yang Z, et al. Adipose-derived mesenchymal stem cells treatments for fibroblasts of fibrotic scar via downregulating TGF- $\beta 1$ and Notch-1 expression enhanced by photobiomodulation therapy. Lasers Med Sci 2019;34:1-10.

14. Zito G, Saotome I, Liu Z, Ferro EG, Sun TY, Nguyen DX, et al. Spontaneous tumour regression in keratoacanthomas is driven by $\mathrm{Wnt} /$ retinoic acid signalling cross-talk. Nat Commun 2014; 5: 3543.

15. Jumper N, Hodgkinson T, Arscott G, Har-Shai Y, Paus R, Bayat A. The AldoKeto Reductase AKR1B10 Is Up-Regulated in Keloid Epidermis, Implicating Retinoic Acid Pathway Dysregulation in the Pathogenesis of Keloid Disease. $J$ Invest Dermatol 2016;136:1500-12. 


\section{Figure Legends}

Figure 1a) The diagram demonstrates the circle of cutaneous repair. A) Non-keloid tendency; (i) a sutured incised surgical wound can become (ii) a normal fine line (linear) scar which can either lead to (iii) a stretched scar or (iv) an atrophic scar. B) Keloid tendency; the incised wound can also become (v) a hypertrophic scar which can either lead to (vi) a contracted scar or (vii) a keloid scar. C) Severe keloid tendency; a keloid scar can be excised surgically: (viii) excised keloid scar (surgery alone) which can also recur: (ix) recurred keloid scar and this can (x) continue to grow and develop into a larger keloid scar.

Figure 1b) A diagram showing the key processes and characteristic features of keloid in relation to quasi-neoplastic tendencies.

Figure 2a) A diagram to demonstrate the quasi-neoplastic tendencies features of keloid disease including; Clinical features (high recurrence, multiple sites, responsive to oncologic therapy), genetic susceptibility (familial, skin type, CNVs, SNPs), tissue characteristics (invasive margins, progressively migratory, hypoxia, mechanosensitive) and molecular targets (NEDD4, TGF $\beta 1$, mTOR pathway, NF-Kb, retinoic acid pathway).

Figure 2b) Key processes contributing to the quasi-neoplastic expression of keloid pathobiology including; proliferative signalling, growth, angiogenesis, invasion, resistance to cell death and response to cancer therapies. 


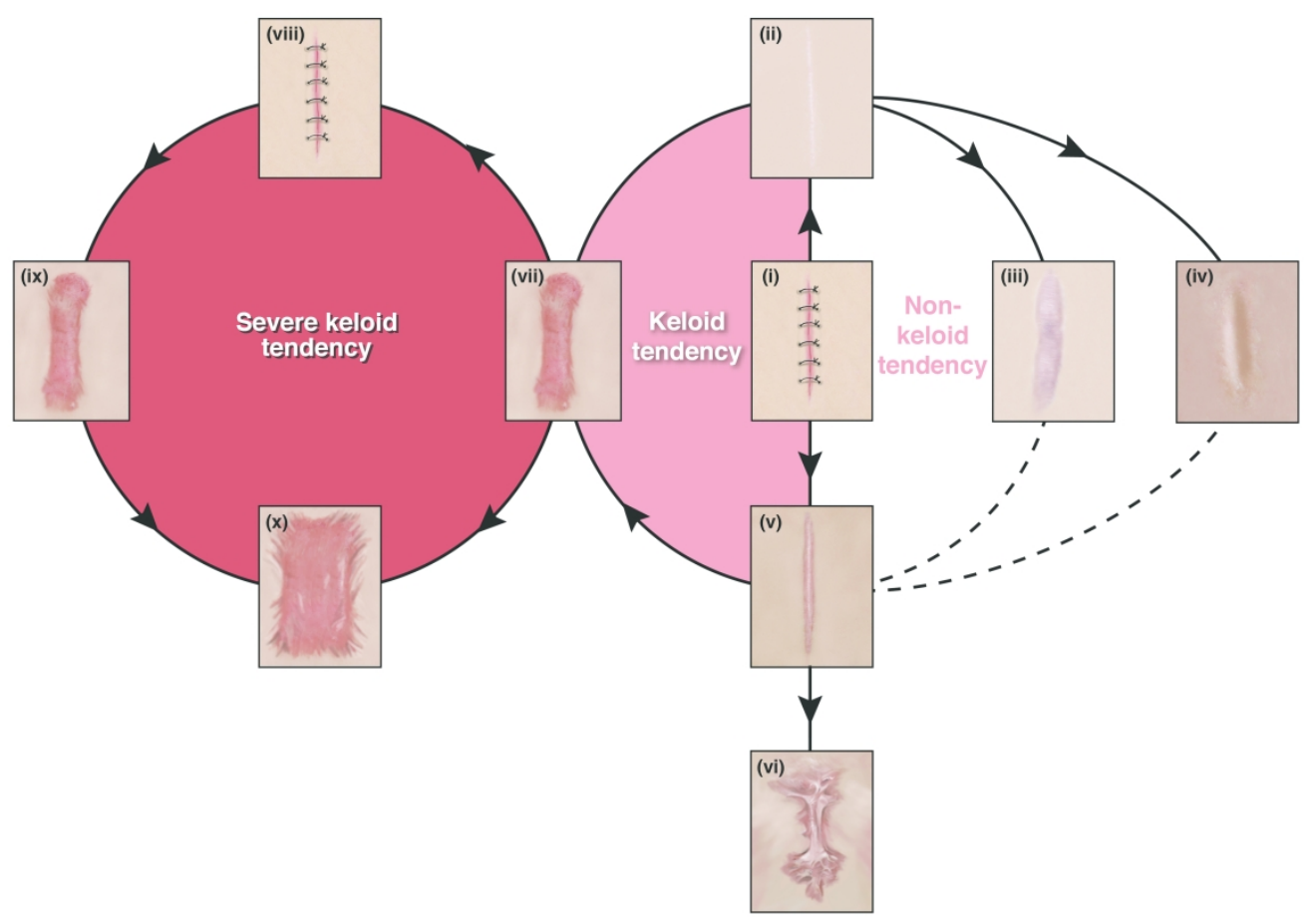

Figure $1 a$

$291 \times 204 \mathrm{~mm}(300 \times 300$ DPI $)$ 
Figure 1b

$278 \times 202 \mathrm{~mm}(150 \times 150 \mathrm{DPI})$ 


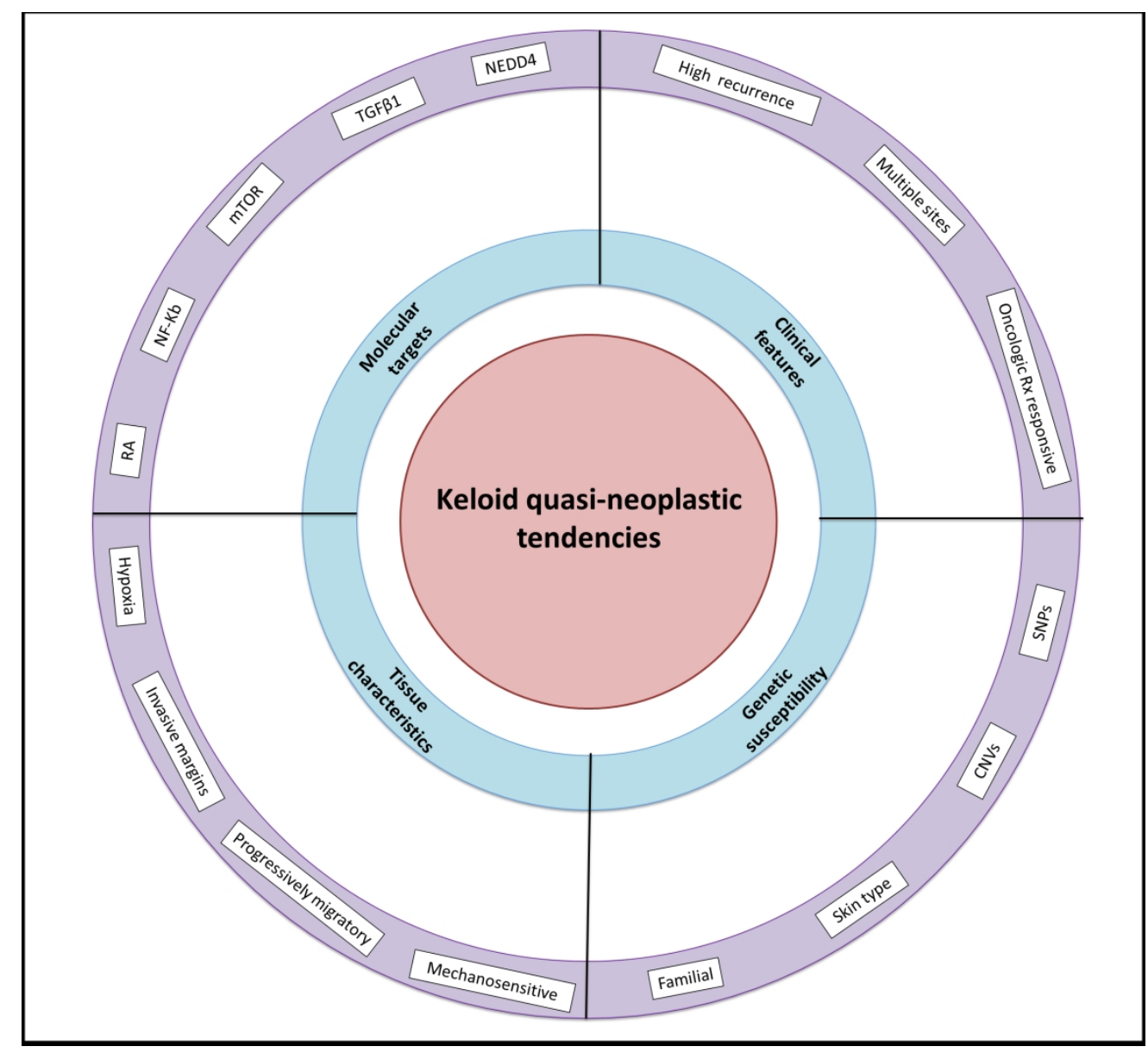

Figure $2 a$

$398 \times 366 \mathrm{~mm}(150 \times 150$ DPI $)$

Wound Repair and Regeneration 


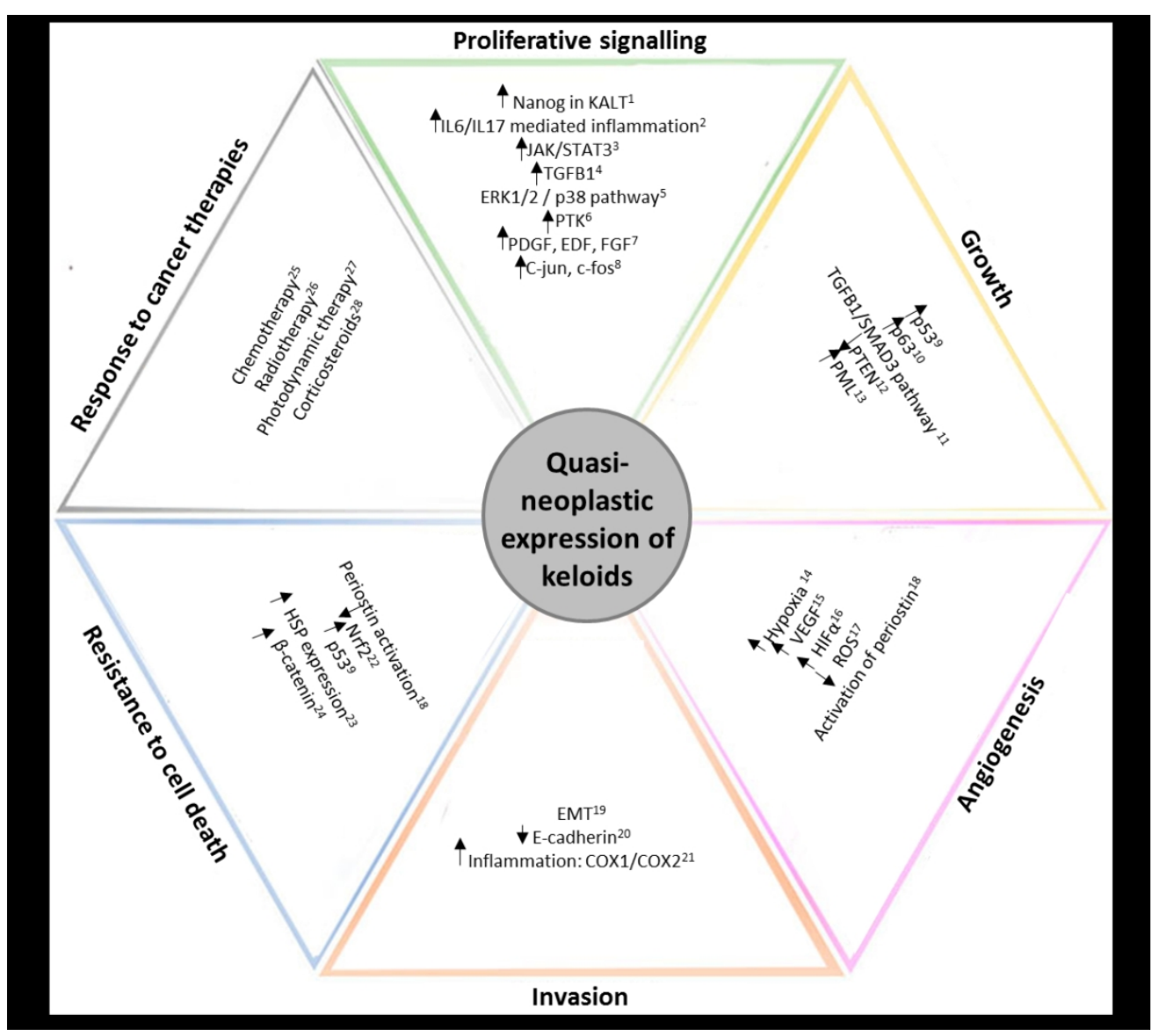

Figure $2 b$

$204 \times 181 \mathrm{~mm}(150 \times 150$ DPI $)$ 


\section{Supplementary References (Figure 2b)}

1. Grant C, Chudakova DA, Itinteang T, Chibnall AM, Brasch HD, Davis PF, et al. . Expression of embryonic stem cell markers in keloid-associated lymphoid tissue. $J$ Clin Pathol 2016;69:643-6.

2. Ghazizadeh M, Tosa M, Shimizu H, Hyakusoku H, Kawanami O. Functional implications of the IL-6 signaling pathway in keloid pathogenesis. J Invest Dermatol 2007;127:98-105.

3. Chang Q, Bournazou E, Sansone P, Berishaj M, Gao SP, Daly L, et al. The IL-6/JAK/Stat3 feed-forward loop drives tumorigenesis and metastasis. Neoplasia 2013;15:848-62.

4. Chipev CC, Simon M. Phenotypic differences between dermal fibroblasts from different body sites determine their responses to tension and TGFbeta1. BMC Dermatol 2002;2:13.

5. Esfahanian N, Shakiba Y, Nikbin B, Soraya H, Maleki-Dizaji N, Ghazi-Khansari M, et al. . Effect of metformin on the proliferation, migration, and MMP-2 and-9 expression of human umbilical vein endothelial cells. Mol Med Rep 2012;5:1068-74.

6.Demoulin JB, Essaghir A. PDGF receptor signaling networks in normal and cancer cells. Cytokine Growth Factor Rev 2014;25:273-83.

7. Haisa M, Okochi H, Grotendorst GR. Elevated levels of PDGF alpha receptors in keloid fibroblasts contribute to an enhanced response to PDGF. J Invest Dermatol 1994;103:560-3.

8. Teofoli P, Barduagni S, Ribuffo M, Campanella A, De Pita O, Puddu P. Expression of Bcl2, p53, c-jun and c-fos protooncogenes in keloids and hypertrophic scars. J Dermatol Sci $1999 ; 22: 31-7$. 
9. Deng CC, Zhu DH, Chen YJ, Huang TY, Peng Y, Liu SY, et al. . TRAF4 promotes fibroblast proliferation in keloids by destabilizing p53 via interacting with the deubiquitinase USP10. J Invest Dermatol 2019;10.1016/j.jid.2019.03.1136

10. Ong CT, Khoo YT, Mukhopadhyay A, Masilamani J, Do DV, Lim IJ, et al. Comparative proteomic analysis between normal skin and keloid scar. Br J Dermatol 2010;162:1302-15.

11. Yao X, Cui X, Wu X, Xu P, Zhu W, Chen X, et al. . Tumor suppressive role of miR1224-5p in keloid proliferation, apoptosis and invasion via the TGF- $\beta 1 / \mathrm{Smad} 3$ signaling pathway. Biochem Biophys Res Commun 2018;495:713-20.

12. Chen C-Y, Chen J, He L, Stiles BL. PTEN: Tumor suppressor and metabolic regulator. Front Endocrinol 2018;9:338.

13. Varmeh S, Egia A, McGrouther D, Tahan SR, Bayat A, Pandolfi PP. Cellular senescence as a possible mechanism for halting progression of keloid lesions. Genes Cancer $2011 ; 2: 1061-6$.

14. Lokmic Z, Musyoka J, Hewitson TD, Darby IA. Hypoxia and hypoxia signaling in tissue repair and fibrosis. Int Rev Cell Mol Biol 2012;296:139-85.

15. Steinbrech DS, Mehrara BJ, Chau D, Rowe NM, Chin G, Lee T, et al. Hypoxia upregulates VEGF production in keloid fibroblasts. Ann Plast Surg 1999;42:514-9.

16. Zhang Q, Wu Y, Ann DK, Messadi DV, Tuan TL, Kelly AP, et al. Mechanisms of hypoxic regulation of plasminogen activator inhibitor-1 gene expression in keloid fibroblasts. J Invest Dermatol 2003;121:1005-12.

17. De Felice B, Wilson RR, Nacca M. Telomere shortening may be associated with human keloids. BMC Med Genet 2009;10:110. 
18. Zhang Z, Nie F, Chen X, Qin Z, Kang C, Chen B, et al. . Upregulated periostin promotes angiogenesis in keloids through activation of the ERK $1 / 2$ and focal adhesion kinase pathways, as well as the upregulated expression of VEGF and angiopoietin1. Mol Med Rep 2015;11:857-64.

19. Hahn JM, McFarland KL, Combs KA, Supp DM. Partial epithelial-mesenchymal transition in keloid scars: regulation of keloid keratinocyte gene expression by transforming growth factor- $\beta 1$. Burns Trauma 2016;4:30.

20. Yan L, Cao R, Wang L, Liu Y, Pan B, Yin Y. Epithelial-mesenchymal transition (EMT) in keloid tissues and TGF-beta1-induced hair follicle outer root sheath keratinocytes. Wound Repair Regen 2015;23:601-10.

21. Abdou AG, Maraee AH, Abd-Elsattar Saif HF. Immunohistochemical evaluation of cox-1 and cox-2 expression in keloid and hypertrophic scar. Am J Dermatopathol 2014;36:311-7.

22. Lee YJ, Kwon SB, Kim CH, Cho HD, Nam HS, Lee SH, et al. Oxidative damage and nuclear factor erythroid 2-related factor 2 protein expression in normal skin and keloid tissue. Ann Dermatol 2015;27:507-16.

23. Lee WJ, Lee JH, Ahn HM, Song SY, Kim YO, Lew DH, et al. Heat shock protein 90 inhibitor decreases collagen synthesis of keloid fibroblasts and attenuates the extracellular matrix on the keloid spheroid model. Plastic Reconstr Surg 2015;136:328e-37e.

24. Yu D, Shang Y, Yuan J, Ding S, Luo S, Hao L. Wnt//-catenin signaling exacerbates keloid cell proliferation by regulating telomerase. Cell Physiol Biochem 2016;39:2001-13.

25. Bijlard E, Steltenpool S, Niessen FB. Intralesional 5-fluorouracil in keloid treatment: a systematic review. Acta Derm Venereol 2015;95:778-82. 
26. Malaker K, Vijayraghavan K, Hodson I, Yafi TA. Retrospective analysis of treatment of unresectable keloids with primary radiation over 25 years. Clin Oncol 2004;16:290-8.

27. Ud-Din S, Thomas G, Morris J, Bayat A. Photodynamic therapy: an innovative approach to the treatment of keloid disease evaluated using subjective and objective non-invasive tools. Arch Dermatol Res 2013;305:205-14.

28. Ud-Din S, Bowring A, Derbyshire B, Morris J, Bayat A. Identification of steroid sensitive responders versus non-responders in the treatment of keloid disease. Arch Dermatol Res $2013 ; 305: 423-32$. 